\title{
Development of a System for Assessing the Ecological State of Water Bodies
}

\author{
Rustam Gakaev* \\ Chechen State University named after A.A. Kadyrova, Grozny, Russia \\ * Corresponding author. Email: rustam.geofak@yandex.ru
}

\begin{abstract}
One of the global tasks of the modern environmental issue is the study of the sustainable development of water bodies, their structure and, most importantly, their rational use. The solution of this urgent problem is practically impossible without researching the components of aquatic ecosystems. These systems preserve the state of water bodies, as well as their trophic potential. Since the state of water bodies is constantly experiencing an intense load of anthropogenic impact, the study of their components is an integral part of the preservation of aquatic ecosystems. Accordingly, the problem of developing methods for reducing anthropogenic impact on the environment and the problem of optimizing the use of natural resources are under intensive study and control. It should be noted that there is a different kind of contradiction between the increase in water consumption.
\end{abstract}

Keywords: anthropogenic impact on the environment, biosphere, preservation of the environment, natural monitoring, sources of pollution.

\section{INTRODUCTION}

The environmental assessment policy of water resources is the identification of the characteristics of their current state both for natural and subject to anthropogenic impact of environmental conditions [3]. The purpose of this assessment is to determine the permissible level of impact, forecast the impact of the use of water resources, assess this existing state. Therefore, we can say that the environmental assessment of water resources includes the achievement of a high level: the quality of water and water bodies, as well as the ecological state of water bodies. Currently, in order to assess the quality of ground and surface waters, as well as their pollution, various methods of assessment and analysis are used: physicochemical and biological methods. When using physicochemical methods, we can quantify, for example, the content of a specific substance in water, but this method does not allow us to judge the state of the aquatic ecosystem as a whole. If we consider biological methods, then on the contrary, this method allows us to qualitatively assess the pollution of water, and also provides an assessment of the state of the ecosystem as a whole. Therefore, these methods are used together.
The ecological state of the world's aquatic ecosystems is largely determined by the ability to maintain their parameters, while being under the influence of various external factors (anthropogenic impact) [1]. The very stability of ecosystems is determined by its species diversity, which can vary from various factors (hydrochemical conditions, trophic level of a water body and other conditions).

Let us add that the ecological state of such an ecosystem can also be characterized by the reversibility of the processes of self-preservation of world water systems. The volume of the considered reversible changes can be characterized by the ability of the water system, which can maintain its properties and its composition unchanged, being under the influence of environmental pollution. If further impact increases, such impact will transfer the system into irreversible changes, while this system will lose its ability to return to its original state even when anthropogenic impact is blocked.

\section{BIOLOGICAL METHODS FOR ASSESSING WATER QUALITY}

If we consider biological methods, then we will start with the fact that they are based on different approaches to the analysis of the state of aquatic 
ecosystems, for example: biocenotic, organismal and population. The organismic approach is an analysis of the physiological characteristics of the analyzed organisms. For example, in order to understand whether the ecosystem has deteriorated or not, they look, for example, at the size of an individual or its internal organs. For the biotest, bacteria from fish, algae, and so on are taken. This method is used to study the operation of treatment facilities. But there is also a drawback associated with the threat of the reaction of certain individuals, since its reaction can be unpredictable [5]. Consider the second approach population-based. It consists in analyzing changes in the rate of reproduction, both in the composition of organisms and in the structure of their population. This includes both changes in the number of individuals and the relationship between different structures. It is used along with the first approach - the organismic approach and, to some extent, does not have the latter's drawbacks; it should be taken into account that the state of the system under consideration is assessed not only by the reaction of several species of the aquatic community. The third approach we are considering - biocenotic - is carried out on the basis of various types of analysis of both composition and trophic structure. Let's look at an example. With a change in the number of different types of species, as well as a change in the contribution of this species to the formation of sustainable development of the ecosystem. It should be noted that this approach is the most basic and most frequently used among all biological methods when it comes to assessing water quality. The most significant drawback of this method is its laboriousness. This method is used both for scientific purposes and for monitoring water bodies of various types [6].

The use of any of the above-mentioned method for assessing both water quality and the state of aquatic ecosystems is focused on the use of certain indicators of various types. For example, physicochemical (such as the limiting pollution index, the water pollution index and other indicators), when using biological methods, for example, the saprobity index, Shannon's index.

\section{ASSESSMENT OF THE ECOLOGICAL STATE OF AQUATIC ECOSYSTEMS USING THE SAPROBITY INDEX}

Saprobity is the degree of saturation of water with decaying organic substances. This degree is established according to the species composition of such organisms. In accordance with this classification, we will consider water bodies according to the following types: oligosaprobic and poly-meso. Polysaprobic reservoirs can be considered in this way: there is no dissolved oxygen in the water, self- purification processes take place at the expense of bacteria, the presence of various kinds of undecomposed proteins, and various anaerobic processes in the aquatic ecosystem are taking place. Let's consider mesosaprobic reservoirs. They are characterized by a large amount of oxygen, also the absence of various kinds of undecomposed proteins, and a low content of both carbon dioxide and hydrogen sulfide. There is a lack of methane, while aerobic processes, on the contrary, prevail [4]. In the self-purification of water, everyone except bacteria, for example, algae, sponges, molluscs, participate. The third type of reservoirs. Oligosaprobic reservoirs contain a high level of oxygen, while there is a low content of carbon dioxide, a large species diversity, highly active self-purification processes take place here.

The saprobity index (S) can be calculated by the following expression [2]:

$$
\mathrm{S}=\Sigma(\mathrm{sh}) / \Sigma(\mathrm{h})
$$

where s-indicator significance of the type $(\mathrm{s}:=1-$ oligosaprobes, $=2$ - alpha-mesosaprobes, $=3$ - betamesosaprobes, $=4$ - polysaprobes); $\mathrm{h}$ is the relative number of individuals of the species $(\mathrm{h}:=1-$ random findings, $=3$ - frequent occurrence, $=5$ - mass development). At $\mathrm{S}=4.0-3.5$ - polysaprobic zone, = 3.5-2.5 - mesosaprobic zone, $=2.5-1.5$ - mesosaprobic zone, $=1.5-1.0-$ oligosaprobic zone, $=0.5-0$ xenosaprobic waters.

It must be said that the biological methods under consideration are very difficult to use in computational practice. These methods lead to a strong complication of the work that must be carried out to assess the state of various types of water bodies. Despite all the general patterns that biological indicators show, there is a great need to consider in more detail the state of the aquatic environment. Also, the considered biological methods are very difficult to apply to determine the goals of forecasting the anthropogenic environment, which is especially important when designing water facilities. It should be taken into account that the combined application of all the considered methods (physicochemical and biological) of the aquatic ecosystem makes it possible to obtain a quantitative and qualitative analysis of the state of the ecosystem as a whole.

will allow the region to develop in a balanced and consistent manner, both in terms of socio-economic application, and in terms of environmental protection and improving the situation of its inhabitants. Currently, appraisal activities are developing mainly in two directions: environmental monitoring of projects and environmental assessment of residential areas. 
An environmental forecast, based on data obtained from the study of materials collected during sampling from wells, is a scientific forecast of the state of the environment caused by human activities or the likely location of the ecosystem. Environmental forecast and assessment of the expected position of the biosphere is the final stage of river and river management [11]. There are rules for predicting the state of the environment, in accordance with which the spread of harmful substances and the regularities of the reaction of various organisms to changes in the environment. Environmental forecasts are supported by information about the state of the environment, both now and in recent days. Through long-term further research, we can demonstrate a desire to improve the environment in this area.

\section{RESULTS AND DISCUSSION}

At present, in all developed countries, the riskbased approach has a central position in the management of anthropogenic water pollution. The assessment of such risks is not only the use of corporate practice, but also a normatively enshrined procedure in the legislation of all developed countries. There are two approaches to assessing the risks of a water ecosystem: the first, when there is an immediate threat to the health of the population, and the second, when the environment and ecosystems are polluted. The specified risk-based approach includes identification, analysis and assessment of risks. The main elements include [4]:

- identification of the risk itself - this is the definition of all situations in which the most terrible risks arise that affect both the development and the state of the system under consideration;

- determination of internal and external parameters by which risk management will be carried out;

- risk analysis - identifying the nature of the risk and determining the level of risk;

- risk assessment - comparison with established risk criteria to determine whether risks are acceptable or acceptable.

- modification (change) of the risk;

- risk monitoring, i.e. risk control process to achieve the set goals.

In the considered system of managing these risks, both in relation to water quality and the state of all aquatic ecosystems, information is used on the extent of the penetration of pollution into water bodies and the degree of their toxicity is considered. In this assessment of the dynamics of the considered characteristics, it is necessary to use mathematical models.
The concept of risk-based is structured. Therefore, one should take into account the probabilistic nature of all parameters that affect the level of the risk group, including hydrochemical ones. Note that it is necessary to analyze the purely statistical characteristics of the estimated indicators. It is clarified that the risk of the concentration of polluting components is always described by the distribution of the Cauchy index. Its main characteristic is the instability of statistical parameters. This means that with an increase in the number of measurements, characteristics such as mean and variance do not tend to a certain value. Therefore, for such an assessment, the use of arithmetic mean values is ineffective. It is recommended to use median methods that are more effective for analyzing the input information of the aquatic ecosystem [5].

The characteristic of the ecological standardization of the current state of the aquatic ecosystem is considered taking into account all fluctuations in the water balance. Also, maintaining all the natural characteristics of the pollution of the aquatic ecosystem is the most important task in the study of water systems. It should be noted that the Interdepartmental Ichthyological Methodology requires improvement; the methodology should be based on the best practice of domestic and foreign experience. Also, in the future, in each large river basin, it is necessary to carry out such work to determine the rationing of ecological flow based on the relationship between all hydrological characteristics.

However, it should be noted that the real impact of all anthropogenic pollution, environmental standards are not assessed by the 360-degree method on the impact on the environment. However, these regulations indicate the level of risk of anthropogenic impact on the environment. In different countries, such existing environmental standards differ in that they often complicate the solution of all transboundary environmental problems and make it necessary to find ways to harmonize all environmental standards. Let us recall that since 2002 the European Union (EU) has had an expensive project "Harmonization of environmental standards of the EU and Russia" [8]. The EU Water Directive (2000) establishes, first of all, the legal basis for the use of all water resources in Europe and, most importantly, provides the basis for their sustainable management. According to the aforementioned Directive, all these measures should be based on the basin principle, since it is a natural unit.

The concept of investigative monitoring is used in all cases of violation of the ecological safety system, when only preventive monitoring measures are insufficient. In addition to all these types of 
monitoring, the participating countries are also obliged to take control of the state of waters in their own territories.

\section{CONCLUSIONS}

It is important to note that there is a problem of assessing and monitoring the quality of the surrounding ecosystem and, in particular, the aquatic environment. This task is one of the most and today the most urgent environmental problem for modern Russia and the whole world as a whole. Therefore, it is necessary to develop a legal framework for regulation, which will determine the permissible impact on the ecosystem as a whole. The legal framework for rationing will also contribute to economic incentives for all economic entities to reduce anthropogenic impact on the environment, necessarily state environmental control at both the federal and regional levels.

It is obvious that work in this direction should be interdisciplinary, interconnected, and most importantly, specialists of all levels should be involved in its implementation. The work of various departments, both water management and other departments that have theoretical training, should be cohesive, and most importantly, practical experience in the field of regulation of anthropogenic load on the aquatic ecosystem.

\section{ACKNOWLEDGMENTS}

The work was carried out within the framework of the state assignment of the Ministry of Science and Higher Education of the Russian Federation (topic No. 075-03-2021-074 / 4).

\section{REFERENCES}

[1] V. A. Bogoslovsky, A. D. Zhigalin, Ecological Geophysics, 2018, pp. 256.

[2] Yu. A. Izrael, Ecology and control of the state of the natural environment, 2019, pp. 560.

[3] O. M. Mazur, Engineering Ecology, 2020, pp. 315 .

[4] Ya. P. Molchanova, Hydrochemical indicators of the state of the environment, 2019, pp. 192.

[5] O. F. Balatsky, L. G. Melnik, A. F. Yakovlev, Economics and Quality of the Environment, 2019, pp. 152.

[6] I. A. Bayrakov, R. A. Gakaev, Anthropogenic impacts on lakes in Chechnya and ways to optimize them. In the collection: Theory and practice of restoration of inland water bodies, 2007, pp. 32-35.

[7] R. A. Gakaev, Hydrological features of mountain lakes in Chechnya. In the collection: Theory and practice of restoration of inland water bodies, 2007, pp. 63-66.

[8] H. B Dulal, R. Dulal, P. K. Yadav, Delivering Green Economy in Asia: The Role of Fiscal Instruments. Futures, 73 (2019) pp. 61-77.

[9] J. Mauritzen, Contractors and Scale: An Empirical Analysis of the California Solar Market, 2016, pp. 105-214.

[10] J. Meckling, L. Hughes, Protecting Solar: Global Supply Chains and Business Power. New Political Economy, 23(1) pp. 88-104.

[11] I. Monasterolo, M. Raberto, The EIRIN Flow-ofFunds Behavioural Model of Green Fiscal Policies and Green Sovereign Bonds. Ecological Economics, 144 (2018) pp. 228-243. 